Article

\title{
Spin Crossover in Bipyridine Derivative Bridged One-Dimensional Iron(III) Coordination Polymer
}

\author{
Ryuta Ishikawa ${ }^{1, *} \mathbb{B}$, Takeshi Noda ${ }^{1}$, Shunya Ueno ${ }^{1}$, Takashi Okubo ${ }^{2}$, Hirofumi Yamakawa ${ }^{3}$, \\ Ken-ichi Sakamoto ${ }^{1}$ and Satoshi Kawata ${ }^{1,3}$ (i) \\ 1 Department of Chemistry, Faculty of Science, Fukuoka University, 8-19-1 Nanakuma, Jonan-ku, \\ Fukuoka 814-0180, Japan; sd172011@cis.fukuoka-u.ac.jp (T.N.); sd152004@cis.fukuoka-u.ac.jp (S.U.); \\ sd192020@cis.fukuoka-u.ac.jp (K.-i.S.); kawata@fukuoka-u.ac.jp (S.K.) \\ 2 Chemistry Course, Department of Science, Faculty of Science and Engineering, Kindai University, \\ 3-4-1 Kowakae, Higashi-Osaka, Osaka 577-8502, Japan; okubo_t@chem.kindai.ac.jp \\ 3 RI center, Fukuoka University, 8-19-1 Nanakuma, Jonan-ku, Fukuoka 814-0180, Japan; \\ hyamakawa@adm.fukuoka-u.ac.jp \\ * Correspondence: ryutaishikawa@fukuoka-u.ac.jp; Tel.: +81-92-871-6631
}

Received: 8 June 2020; Accepted: 28 June 2020; Published: 1 July 2020

\begin{abstract}
Herein, the syntheses, solid-state molecular structures, and characterization of two types of one-dimensional $\mathrm{Fe}^{\mathrm{III}}$ coordination polymers showing thermally induced spin crossover are reported. The reaction of [ $\mathrm{Fe}(\mathrm{acen}) \mathrm{Cl}]\left(\right.$ acen $^{2-}=N, N^{\prime}$-ethylenebis(acetylacetonylideneaminate) with $3,3^{\prime}$-bpy or 4,4'-bpy (bpy = bipyridine) produced zigzag and linear one-dimensional chain complexes, [Fe(acen)(3,3'-bpy)][BPh 4 (1) or $\left[\mathrm{NEt}_{3} \mathrm{H}\right]\left[\mathrm{Fe}(\right.$ acen $)\left(4,4^{\prime} \text {-bpy)][BPh }\right]_{2} \cdot 0.5\left(4,4^{\prime}\right.$-bpy) (2), respectively, as confirmed by single crystal X-ray diffraction analysis. Variable-temperature single crystal X-ray diffraction measurements, continuous-wave $\mathrm{X}$-band electron paramagnetic resonance (EPR) spectra, ${ }^{57} \mathrm{Fe}$ Mössßauer spectra, and DC magnetic susceptibility data revealed that complex $\mathbf{1}$ exhibited a gradual and complete spin crossover at a transition temperature of $212 \mathrm{~K}$, while complex 2 undergoes an incomplete spin crossover even at $400 \mathrm{~K}$.
\end{abstract}

Keywords: iron(III); Schiff base ligand; bipyridine ligand; crystal structure; spin crossover; EPR spectroscopy; Mössßauer spectroscopy

\section{Introduction}

First-row transition metal complexes with a $\mathrm{d}^{4}-\mathrm{d}^{7}$ electron configuration can adopt two electron configurations, high spin (HS), and low spin (LS), which differ in terms of spin ground states. When both HS and LS states are energetically similar, switching between the two spin states reversibly occurs when external stimuli including temperature, pressure, light irradiation, and magnetic fields are applied in a process known as spin crossover (SCO) [1-11]. Complexes exhibiting SCO have attracted significant attention because of their wide range of potential applications, such as in thermochromic displays, actuators, (multi-modal) sensors, and data storage systems, as well as in molecular spintronics [12-19]. Moreover, a number of approaches of the nanostructural patterning based on SCO complexes have also been studied [20-26].

The most extensively studied SCO moieties are $\mathrm{Fe}^{\mathrm{II}}$ complexes with a $3 \mathrm{~d}^{6}$ electron configuration because of a distinct spin transition from a paramagnetic HS state $(S=2)$ to a diamagnetic LS state $(S=0)$, or vice versa, which generally show abrupt spin transitions and high cooperativity in the solid state [1-11]. In contrast, $\mathrm{Fe}^{\mathrm{III}} \mathrm{SCO}$ complexes have not been as extensively reported as $\mathrm{Fe}^{\mathrm{II}}$ SCO complexes, mostly due to the lack of cooperativity associated with $\mathrm{Fe}^{\mathrm{III}}$ SCO complexes $[27,28]$. To overcome this obstacle, several fascinating $\mathrm{Fe}^{\mathrm{III}} \mathrm{SCO}$ complexes that exhibit high cooperativity have 
been realized by introducing relatively weak supramolecular contacts, including hydrogen bonding and $\pi-\pi$ stacking interactions between SCO active centers in the packed crystal. These have also been shown to result in abrupt spin transition, multistep spin transition, wide thermal hysteresis loop, and light-induced excited spin state trapping effect $[27,28]$. However, previously reported almost $\mathrm{Fe}^{\mathrm{III}} \mathrm{SCO}$ complexes are discrete mononuclear and dinuclear complexes. To further expand the basic understanding of magnetostructural correlations in highly cooperative $\mathrm{Fe}^{\mathrm{III}}$ SCO complexes, the development of $\mathrm{Fe}^{\mathrm{III}} \mathrm{SCO}$ coordination polymer candidates with structurally high dimensionality is necessary. As an initial attempt to create novel Fe $\mathrm{IIII}^{\mathrm{SCO}}$ coordination polymers, a one-dimensional (1D) coordination polymer structure was proposed.

To date, SCO-active Fe ${ }^{\mathrm{III}}$ complexes have been explored using Schiff base ligands with a $\mathrm{N}_{4} \mathrm{O}_{2}$ coordination environment $[27,28]$. From this perspective, constructing coordination polymers can be achieved by crystal engineering via combination of an $\mathrm{Fe}^{\mathrm{III}}$ precursor with a macrocyclic-type Schiff base ligand furnished with a $\mathrm{N}_{2} \mathrm{O}_{2}$ coordination donor set, as a building block and a N-donor bridging ligand.

Herein, the syntheses, solid-state molecular structures, and characterization of two new one-dimensional $\mathrm{Fe}{ }^{\mathrm{III}} \mathrm{SCO}$ coordination polymers composed of $[\mathrm{Fe}(\text { acen })]^{+}\left(\right.$acen $^{2-}=N, N^{\prime}$-ethylenebis

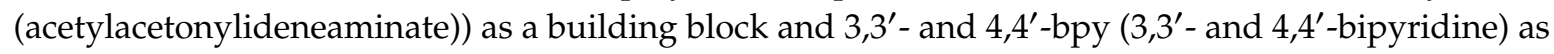
bridging ligands are reported.

\section{Results and Discussion}

\subsection{Syntheses and General Characterization}

The complex, $\left[\mathrm{Fe}(\right.$ acen$\left.)\left(3,3^{\prime}-\mathrm{bpy}\right)\right]\left[\mathrm{BPh}_{4}\right](\mathbf{1})$, was obtained via stepwise assembly reactions. The first reaction is the synthesis of the cationic $\mathrm{Fe}^{\mathrm{III}}$ building block, $[\mathrm{Fe}(\mathrm{acen})]^{+}$, which is readily prepared via the reaction of acen ${ }^{2-}$ deprotonated by triethylamine $\left(\mathrm{NEt}_{3}\right)$ in situ with anhydrous $\mathrm{FeCl}_{3}$ in $\mathrm{EtOH}[29,30]$. Subsequent reaction of $[\mathrm{Fe}(\text { acen })]^{+}$and 3,3'-bpy with $\mathrm{NaBPh}_{4}$ in a 1:1:1 molar ratio in $\mathrm{MeOH}$ afforded dark green block-shaped crystals of $\mathbf{1}$, suitable for single crystal X-ray diffraction (SCXRD) analysis. Unfortunately, the single crystals suitable for SCXRD analysis were not obtained using the same assembly reaction as that for $\mathbf{1}$ with $4,4^{\prime}$-bpy instead of $3,3^{\prime}$-bpy. Alternatively, isolation of dark green plate-shaped crystals of $\left[\mathrm{NEt}_{3} \mathrm{H}\right]\left[\mathrm{Fe}(\mathrm{acen})\left(4,4^{\prime}-\mathrm{bpy}\right)\right]\left[\mathrm{BPh}_{4}\right]_{2} \cdot 0.5\left(4,4^{\prime}\right.$-bpy) (2) via one-pot reaction between $\mathrm{H}_{2}$ acen, $\mathrm{NEt}_{3}, \mathrm{FeCl}_{3}, 4,4^{\prime}$-bpy, and $\mathrm{NaBPh}_{4}$ in a 1:2:1:1:1 molar ratio in $\mathrm{MeOH}$ was successful.

Both 1 and $\mathbf{2}$ showed characteristic Fourier-transform infrared (FTIR) peaks, indicating the presence of $\mathrm{BPh}_{4}{ }^{-}\left(\sim 700\right.$ and $\left.730 \mathrm{~cm}^{-1}\right)$ and a Fe $\mathrm{Fe}^{\mathrm{III}}$-coordinated imine moiety $\left(\sim 1580 \mathrm{~cm}^{-1}\right)$, as indicated in Figure S1. The phase purity of $\mathbf{1}$ and $\mathbf{2}$ was confirmed via powder X-ray diffraction (PXRD) measurements. Experimental PXRD patterns of polycrystalline $\mathbf{1}$ and $\mathbf{2}$ were in agreement with the calculated patterns based on SCXRD data for the complexes. Therefore, no complexes exhibited crystal polymorphism and both polycrystalline samples adopted a uniform crystalline phase (Figure S2). The purities of 1 and 2 were confirmed by elemental analyses (Section 3). Thermogravimetric analyses (TGA) indicated that polycrystalline samples 1 and 2 are thermally stable up to $\sim 420 \mathrm{~K}$ (Figure S3).

\subsection{Structural Descriptions}

The SCXRD measurements of $\mathbf{1}$ and $\mathbf{2}$ were performed at 100 and $300 \mathrm{~K}$ (Table S1).

At both temperatures, complex 1 crystallized in a monoclinic space group $P 2_{1} / c$, with the asymmetric unit containing $\left[\mathrm{Fe}(\text { acen })\left(3,3^{\prime}-\mathrm{bpy}\right)\right]^{+}$and $\mathrm{B} \mathrm{BPh}_{4}{ }^{-}$anion (upper part of Figure 1a). The $\mathrm{Fe}^{\mathrm{III}}$ center approximated a distorted octahedral geometry (octahedral distortion parameter, $\Sigma$ [31]; $\Sigma=35.82(6)$ and $36.81(7)^{\circ}$ at 100 and $300 \mathrm{~K}$ ), with an equatorial plane occupied by a $\mathrm{N}_{2} \mathrm{O}_{2}$ coordination donor from an acen ${ }^{2-}$ ligand, while each axial site was bridged via two $\mathrm{N}$ ends of a 3,3'-bpy ligand in a trans configuration with dihedral angles between pyridine rings of 36.35 and $32.68^{\circ}$ at 100 and $300 \mathrm{~K}$, forming a zigzag 1D chain (lower part of Figure 1a). At $100 \mathrm{~K}$, the average Fe-O $\mathrm{O}_{\text {equatorial, }}$ 
$\mathrm{Fe}-\mathrm{N}_{\text {equatorial, }}$ and Fe- $\mathrm{N}_{\text {axial }}$ distances were consistent with those in the LS Fe ${ }^{\mathrm{III}}$ complexes with similar coordination environments of related Fe ${ }^{\mathrm{III}}$ (acen)-type complexes (Table S2) [32-38]. In contrast, the corresponding distances at $300 \mathrm{~K}$ were significantly longer than those observed at $100 \mathrm{~K}$, suggesting a thermally induced SCO between 100 and $300 \mathrm{~K}$ (Table 1, Table 2 and Table S2). The changes of these coordination bond distances are comparable with those previously reported for $\mathrm{Fe}^{\mathrm{III}}$ (acen)-type SCO complexes (Table 2 and Table S2). No lattice solvent molecules were present in the crystal packing and the intrachain $\mathrm{Fe}^{\mathrm{III}} \ldots \mathrm{Fe}^{\mathrm{III}}$ separations were determined to be 9.5895(7) and 9.8189(7) $\AA$ at 100 and $300 \mathrm{~K}$, respectively. Each zigzag 1D chain of 1 propagated along the crystallographic $c$ axis in the crystal packing, separated by bulky $\mathrm{BPh}_{4}{ }^{-}$anions, with the closest interchain $\mathrm{Fe}^{\mathrm{III}} . . . \mathrm{Fe} \mathrm{e}^{\mathrm{III}}$ separation of 9.3105(5) and 9.6025(8) $\AA$ at 100 and $300 \mathrm{~K}$, respectively (Figure 2a).
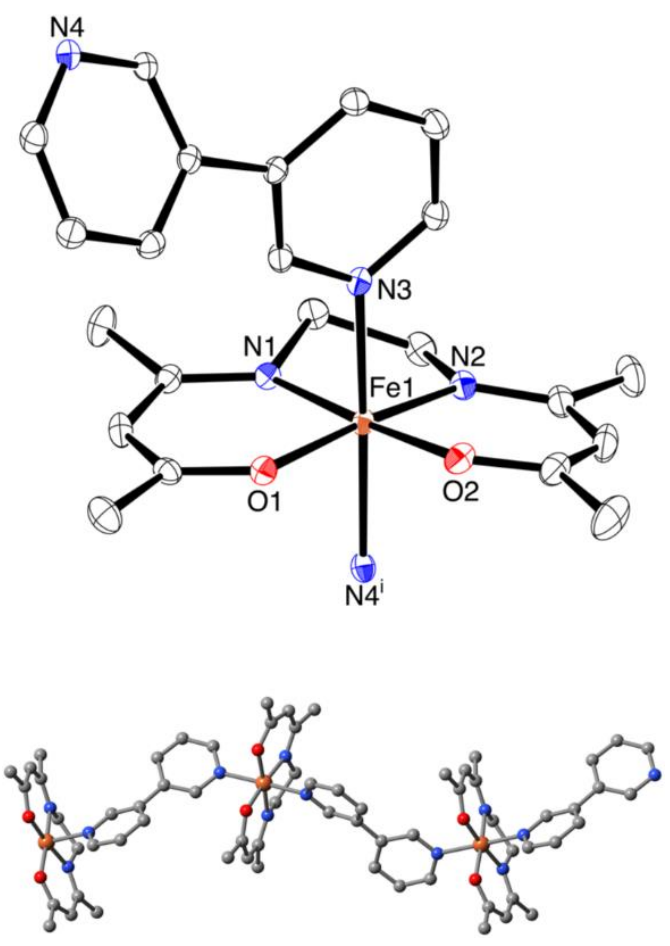

(a)
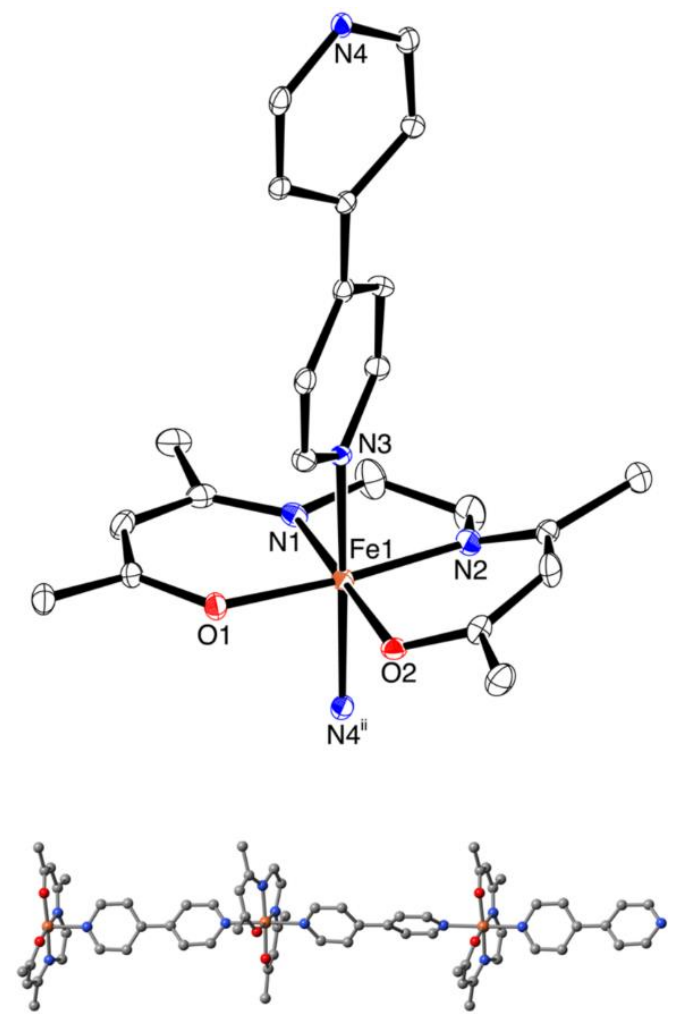

(b)

Figure 1. Solid-state molecular structures at $100 \mathrm{~K}$ with thermal ellipsoids drawn at $30 \%$ probability level (upper), showing numbering schemes for central metal and coordinating atoms only, where symmetry codes: (i) and (ii) $x,-y+3 / 2, z-1 / 2$ and their $1 \mathrm{D}$ chain arrangements (lower) for (a) 1 and (b) 2. Orange, gray, blue, and red spheres represent Fe, C, N, and $\mathrm{O}$ atoms. $\mathrm{H}$ atoms are omitted for clarity.

Complex 2 crystallized in the monoclinic space group $P 2_{1} / n$ at 100 and $300 \mathrm{~K}$. The asymmetric unit consisted of a $\left[\mathrm{Fe}(\mathrm{acen})\left(4,4^{\prime}-\mathrm{bpy}\right)\right]^{+}$unit, a $\mathrm{NEt}_{3} \mathrm{H}^{+}$cation, two $\mathrm{BPh}_{4}{ }^{-}$anions, and half of a non-coordinating 4,4'-bpy molecule. Similar to 1 , the $\mathrm{Fe}^{\mathrm{III}}$ center was situated in a distorted octahedral geometry $\left(\Sigma=32.8(1)\right.$ and $26.92(9)^{\circ}$ at 100 and $300 \mathrm{~K}$, respectively), with the same coordination environment as 1 (the upper part of Figure 1b). No significant changes in the coordination bonds were observed at 100 or $300 \mathrm{~K}$, while coordination bond angles did show some changes (Table 1, Table 2 and Table S2). Unlike 1, the Fe $\mathrm{F}^{\mathrm{III}}$ center linearly coordinated to neighboring Fe $\mathrm{Fe}^{\mathrm{III}}$ centers via bridging 4,4'-bpy ligands, thereby adopting a linear 1D chain arrangement. Neighboring 1D chains were aligned parallel along the $a-c$ direction, with intrachain $\mathrm{Fe}^{\mathrm{III}} \ldots \mathrm{Fe} \mathrm{FII}^{\mathrm{III}}$ separations of 11.098(1) and 11.1610(8) $\AA$ at 100 and $300 \mathrm{~K}$, respectively (lower part of Figure 1b). Remarkable hydrogen bonding interactions were observed between the $\mathrm{NEt}_{3} \mathrm{H}^{+}$cations and pyridyl $\mathrm{N}$ ends of a non-coordinating 
4,4'-bpy molecule in the crystal packing (Figure S4). This dense assembly containing cationic 1D chains of $\left[\mathrm{Fe}(\mathrm{acen})\left(4,4^{\prime} \text {-bpy }\right)\right]^{+}, \mathrm{BPh}_{4}{ }^{-}$anions, and hydrogen bonding between $\mathrm{NEt}_{3} \mathrm{H}^{+}$cations and $4,4^{\prime}$-bpy molecule excluded lattice solvent molecules in the crystal packing (Figure 2b). The closest interchain $\mathrm{Fe}^{\mathrm{III}} \ldots \mathrm{Fe} \mathrm{FI}^{\mathrm{III}}$ separations were 8.707(1) and 8.9505(8) $\AA$ at 100 and $300 \mathrm{~K}$, respectively.

Although the coordination environments of $\mathbf{1}$ and $\mathbf{2}$ were similar, with the exception of chain topology and arrangement, different conformations of the $\mathrm{C}_{2} \mathrm{~N}_{2}$ backbone were observed with respect to the acen ${ }^{2-}$ ligand moiety. In particular, the acen ${ }^{2-}$ geometry of $\mathbf{1}$ adopted a meso conformation, whereas that of $\mathbf{2}$ adopted an envelope conformation. Therefore, the substantial distortion of the acen ${ }^{2-}$ geometry induces the LS state for complexes containing $[\mathrm{Fe}(\mathrm{acen})]^{+}$, consistent with previous studies (Table S2) [32-38].

Table 1. Selected bond distances $(\AA)$ and angles $\left({ }^{\circ}\right)^{1}$ for $\mathbf{1}$ and 2 at 100 and $300 \mathrm{~K}$.

\begin{tabular}{|c|c|c|c|c|}
\hline & $1(100 \mathrm{~K})$ & $1(300 \mathrm{~K})$ & $2(100 \mathrm{~K})$ & $2(300 \mathrm{~K})$ \\
\hline \multicolumn{5}{|c|}{ Bond distances } \\
\hline Fe1-N1 & $1.911(2)$ & $2.025(2)$ & $1.890(3)$ & $1.912(3)$ \\
\hline Fe1-N2 & $1.921(2)$ & $2.039(2)$ & $1.912(3)$ & $1.922(2)$ \\
\hline Fe1-N3 & $2.048(2)$ & $2.199(2)$ & $2.004(3)$ & $2.036(3)$ \\
\hline $\mathrm{Fe} 1-\mathrm{N} 4^{\mathrm{i}}$ & $2.049(2)$ & $2.188(2)$ & $1.998(4)$ & $2.035(2)$ \\
\hline Fe1-O1 & $1.912(1)$ & $1.929(1)$ & $1.906(2)$ & $1.904(2)$ \\
\hline $\mathrm{Fe} 1-\mathrm{O} 2$ & 1.901(1) & $1.921(2)$ & $1.896(2)$ & $1.894(2)$ \\
\hline \multicolumn{5}{|c|}{ Bond angles } \\
\hline N1-Fe1-N2 & $85.51(7)$ & 81.91(7) & 85.1(1) & $84.7(1)$ \\
\hline N1-Fe1-N3 & $88.33(6)$ & $94.49(6)$ & $88.2(1)$ & $88.9(1)$ \\
\hline $\mathrm{N} 1-\mathrm{Fe} 1-\mathrm{N} 4{ }^{\mathrm{i}}$ & $94.10(6)$ & $88.98(6)$ & $94.1(1)$ & $93.8(1)$ \\
\hline N2-Fe1-N3 & $93.62(6)$ & $90.58(6)$ & $93.4(1)$ & $92.5(1)$ \\
\hline N2-Fe1-N4 ${ }^{\mathrm{i}}$ & $90.62(6)$ & $94.72(7)$ & 89.3(1) & $90.0(1)$ \\
\hline N1-Fe1-O1 & $94.51(6)$ & $90.77(6)$ & $93.8(1)$ & $93.23(9)$ \\
\hline N2-Fe1-O2 & $93.77(6)$ & $90.15(7)$ & $94.4(1)$ & $93.89(9)$ \\
\hline N3-Fe1-O1 & $91.50(6)$ & $84.23(6)$ & $89.1(9)$ & $89.79(8)$ \\
\hline N3-Fe1-O2 & $87.87(6)$ & $88.94(6)$ & $86.9(9)$ & $87.18(8)$ \\
\hline N4 ${ }^{\text {i_-Fe1-O1 }}$ & $84.27(6)$ & $90.88(6)$ & $88.2(9)$ & $87.82(9)$ \\
\hline $\mathrm{N} 4{ }^{\mathrm{i}}-\mathrm{Fe} 1-\mathrm{O} 2$ & $89.76(6)$ & $88.30(6)$ & $90.8(9)$ & $90.19(9)$ \\
\hline $\mathrm{O} 1-\mathrm{Fe} 1-\mathrm{O} 2$ & $86.56(6)$ & $97.47(6)$ & $86.9(9)$ & $88.30(8)$ \\
\hline N3-Fe1-N4 i & $175.27(6)$ & $174.03(6)$ & $176.6(1)$ & $176.50(9)$ \\
\hline N1-Fe1-O2 & $176.08(5)$ & $171.36(7)$ & 175.1(1) & $175.8(1)$ \\
\hline N2-Fe1-O1 & $174.88(6)$ & $170.68(7)$ & 177.3(1) & $176.9(1)$ \\
\hline$\Sigma$ & $35.82(6)$ & $36.70(6)$ & $32.8(1)$ & $26.92(9)$ \\
\hline
\end{tabular}

${ }^{1}$ Symmetry codes: ${ }^{\mathrm{i}} x,-y+3 / 2, z-1 / 2$.

Table 2. Changes of coordination bond distances $(\AA)^{1}$ between the LS and HS states in 1, 2, related complexes.

\begin{tabular}{ccccc}
\hline Complex $^{2}$ & $\boldsymbol{\Delta} \mathbf{F e}-\mathbf{O}_{\text {equatorial }}$ & $\Delta \mathbf{F e}-\mathbf{N}_{\text {equatorial }}$ & $\Delta \mathbf{F e}-\mathbf{N}_{\text {axial }}$ & Reference \\
\hline$\left[\mathrm{Fe}\left(\right.\right.$ acen)(3,4-Me $\left.\mathrm{Mpy}_{2}\right]\left[\mathrm{BPh}_{4}\right]$ & 0.024 & 0.141 & 0.150 & {$[34]$} \\
{$\left[\mathrm{Fe}(\right.$ acen) $(\mathrm{bpyp})]\left[\mathrm{BPh}_{4}\right]$} & 0.020 & 0.138 & 0.165 & {$[35,36]$} \\
{$\left[\mathrm{Fe}(\right.$ acen)(bimb) $]\left[\mathrm{BPh}_{4}\right]$} & 0.030 & 0.117 & 0.116 & {$[36]$} \\
$\mathbf{1}$ & 0.019 & 0.116 & 0.146 & this work \\
$\mathbf{2}$ & 0.002 & 0.016 & 0.034 & this work \\
\hline
\end{tabular}

${ }^{1}$ Average values. ${ }^{2}$ Ligand abbreviations: 3,4-Me $2 \mathrm{py}=3,4$-dimethylpyridine, bpyp = 1,3-bis(4-pyridyl)propane, and bimb $=$ bimb $=1,4$-bis(imidazolyl)butane. 


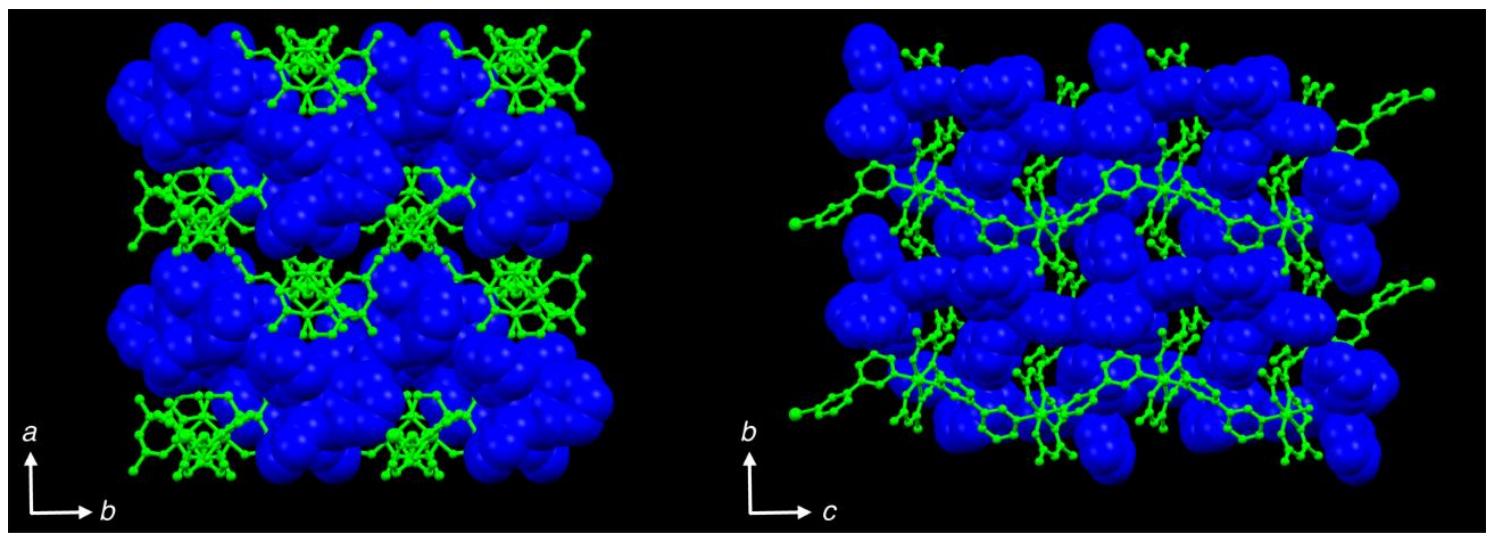

(a)

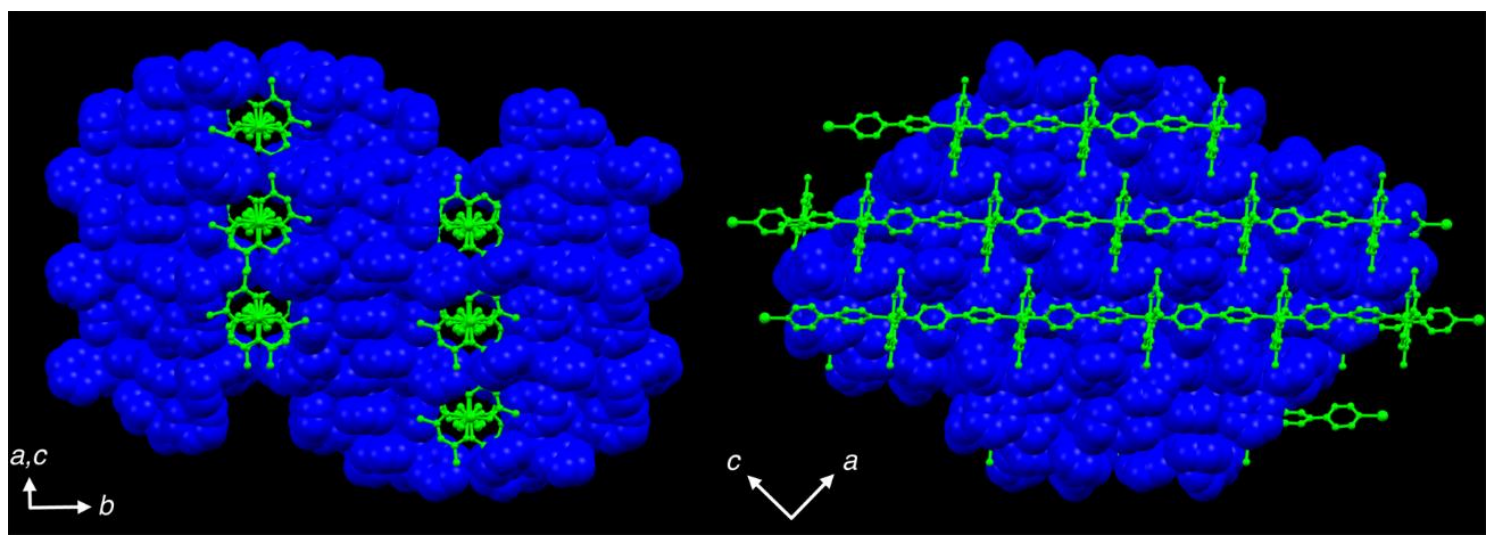

(b)

Figure 2. Crystal packing diagrams of (a) 1 and (b) 2 at $100 \mathrm{~K}$, showing top (left) and side (right) arrangements of the cationic $1 \mathrm{D}$ chains as a green colored ball and stick model and other molecules as a blue colored space-filling model. $\mathrm{H}$ atoms are omitted for clarity.

\subsection{Continuous-Wave X-Band Electron Paramagnetic Spectroscopy}

Continuous-wave X-band electron paramagnetic resonance (CW X-band EPR) spectroscopy is useful, because $\mathrm{Fe}^{\mathrm{III}}$ complexes with octahedral coordination geometry are Kramers systems, and are generally EPR-active at X-band frequencies $\left(\sim 0.3 \mathrm{~cm}^{-1}\right)$ under magnetic fields $(\sim 1 \mathrm{~T})$, regardless of the electron configuration of the Fe $\mathrm{III}^{\mathrm{II}}$ center (i.e., $\mathrm{LS}(S=1 / 2)$ or $\left.\mathrm{HS}(S=5 / 2)\right)$. However, it should be noted that for the HS Fe ${ }^{\mathrm{III}}$ center effective $g$ values were obtained, which are only useful in a qualitative sense. The lack of quantitation arises from the dependence on the magnitude of the zero-field splitting energies for the HS state of $S=5 / 2$ [39]. The CW X-band EPR spectra of polycrystalline $\mathbf{1}$ and 2 were collected at 90-280 K (Figure 3).

At low temperatures, the EPR spectra of 1 can be described as a complete and well-resolved LS state, $S=1 / 2$, indicating highly rhombicity of the $g_{x}, g_{y}$, and $g_{z}$ values $(1.919,2.086$, and 2.408, respectively), and an average $g$ value of 2.138 (Figure 3a). The observed $g$ values are characteristic of LS Fe ${ }^{\mathrm{III}}$ complexes with similar coordination environments [40-47]. With the increasing temperature, the EPR signals centered at the average $g$ value of 2.138 for $\mathbf{1}$ gradually broadened from rhombic to isotropic symmetry, and became steadily indistinct. Instead, a new signal centered at approximately $g=4.3$ appeared and steadily grew, corresponding to a gradual change from the LS to HS state with highly rhombicity $(E \approx D / 3$; where $D$ and $E$ are the axial and rhombic zero-field splitting parameters, respectively) [48], ultimately becoming very broad dominated by the HS signal at $280 \mathrm{~K}$. 
The low temperature EPR spectra of 2 showed isotropic signals centered at $g=2.137$, which is considerably similar to the average $g$ value of 2.138 observed for the LS state of $\mathbf{1}$ (Figure $3 b$ ). With increasing temperature, the EPR signals of 2 showed slight line broadening, while a strongly rhombic HS signal at $g \approx 4.3$ appeared only at the high temperature region and was not overly dominant. Therefore, the Fe ${ }^{\mathrm{III}}$ center of 2 remained in a quasi-LS state throughout the temperature range measured.

Therefore, both 1 and 2 undergo thermally induced SCO from LS to HS in the solid-state. These results also suggest that $\mathbf{1}$ exhibited a gradual and complete SCO, while $\mathbf{2}$ displayed incomplete SCO over the temperature range measured herein.

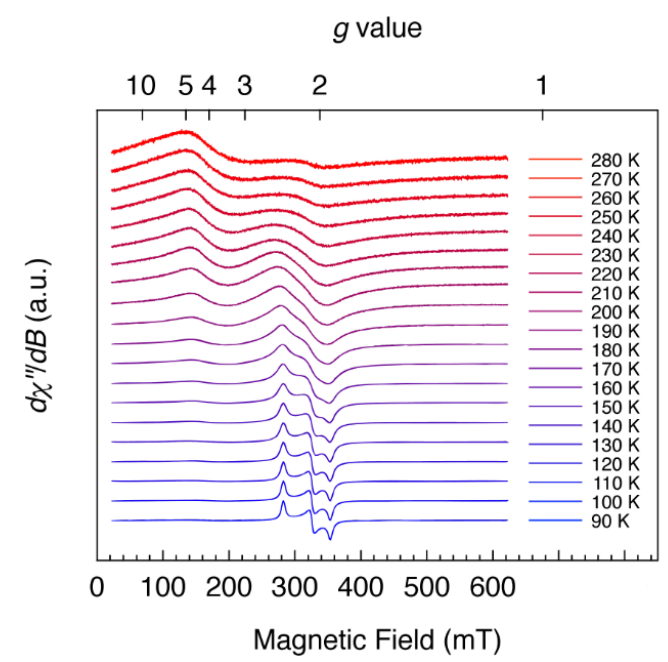

(a)

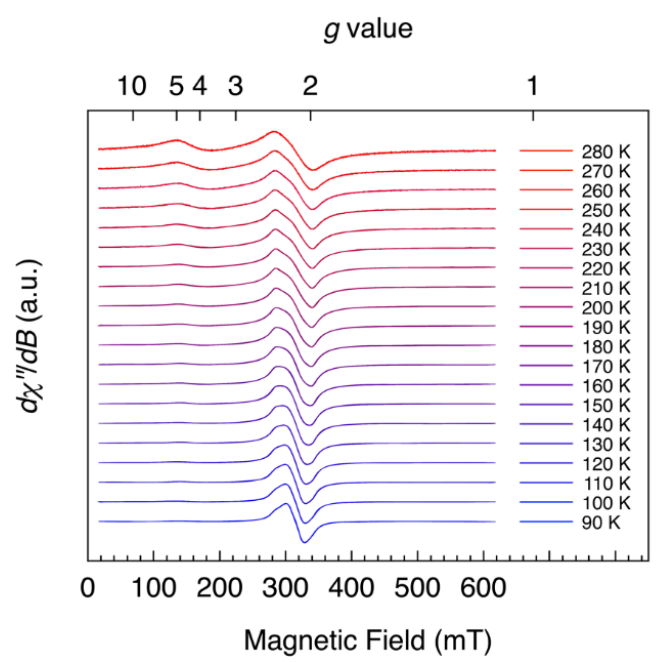

(b)

Figure 3. Continuous-wave (CW) X-band electron paramagnetic resonance (EPR) spectra of polycrystalline samples for (a) $\mathbf{1}$ and (b) 2 collected in the temperature $90-280 \mathrm{~K}$ in $10 \mathrm{~K}$ intervals.

\subsection{Magnetic Properties}

To further prove thermally induced SCO for $\mathbf{1}$ and $\mathbf{2}$, the temperature dependence of molar DC magnetic susceptibility $\left(\chi_{\mathrm{M}}\right)$, measurements were performed using a SQUID magnetometer on the polycrystalline samples over the temperature range of $2-400 \mathrm{~K}$, under an applied field of $0.5 \mathrm{~T}$ at a scan rate of $2 \mathrm{~K} \mathrm{~min}^{-1}$ (Figure 4 ).

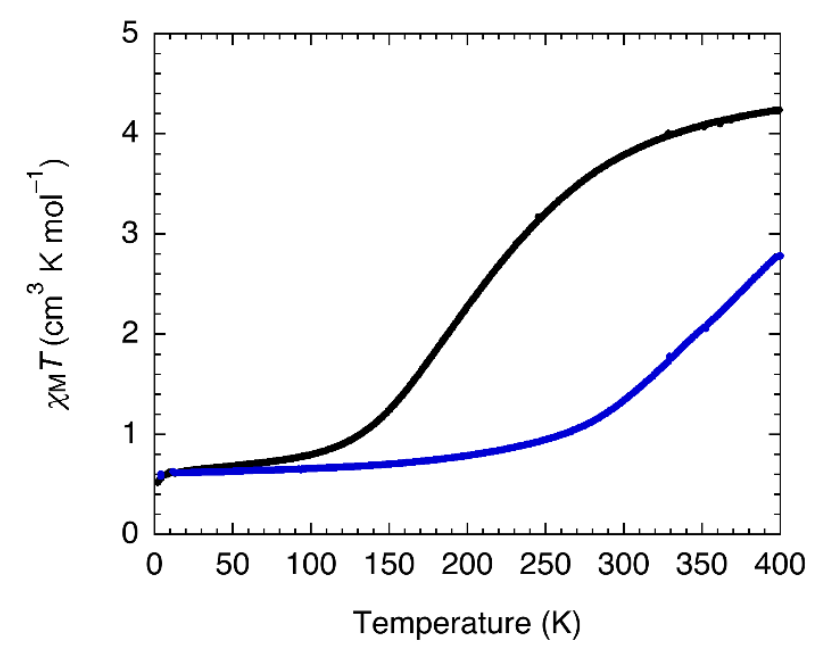

Figure 4. Plots of the $\chi_{\mathrm{M}} T$ versus temperature over the temperature range $2-400 \mathrm{~K}$ in an applied dc field of $0.5 \mathrm{~T}$ at scan rate of $2 \mathrm{~K} \mathrm{~min}^{-1}$ for 1 (black) and 2 (blue). 
At $2 \mathrm{~K}$, the $\chi_{\mathrm{M}} T$ ( $\chi_{\mathrm{M}}$ times temperature) value for 1 was determined to be $0.52 \mathrm{~cm}^{3} \mathrm{~K} \mathrm{~mol}^{-1}$, which is consistent with the expected $\chi_{\mathrm{M}} T$ value at $g>2$ for an essentially complete LS state for the Fe ${ }^{\mathrm{III}}$ center. With the increasing temperature, the $\chi_{M} T$ values increased steadily, with a more rapid increase in the $\chi_{\mathrm{M}} T$ data between 120 and $300 \mathrm{~K}$, which is indicative of thermally induced SCO. This thermal spin transition $\left(T_{1 / 2}\right)$ occurred at $210 \mathrm{~K}$ without thermal hysteresis, as confirmed by differential scanning calorimetry (DSC; Figure S5). At temperatures of $>120 \mathrm{~K}$, the $\chi_{\mathrm{M}} T$ values again gradually increased to $4.24 \mathrm{~cm}^{3} \mathrm{~K} \mathrm{~mol}^{-1}$ at $400 \mathrm{~K}$, characteristic of a fully HS state for the Fe $\mathrm{III}^{\mathrm{III}}$ center. The $\chi_{\mathrm{M}} T$ value for 2 was approximately $0.60 \mathrm{~cm}^{3} \mathrm{~K} \mathrm{~mol}^{-1}$ at $2 \mathrm{~K}$, remaining constant up to $200 \mathrm{~K}$, and then gradually increases to $2.78 \mathrm{~cm}^{3} \mathrm{~K} \mathrm{~mol}^{-1}$ at $400 \mathrm{~K}$. In contrast to 1 , the Fe $\mathrm{Fe}^{\mathrm{III}}$ center of 2 remained in a near LS state even at $400 \mathrm{~K}$ (inflection point at $380 \mathrm{~K}$ ), undergoing incomplete SCO.

To quantify the energy separation $(\Delta E)$ between the zero-point levels of the $\mathrm{LS}\left({ }^{2} \mathrm{~T}_{2}\right)$ and $\mathrm{HS}\left({ }^{6} \mathrm{~A}_{1}\right)$ states in 1, which exhibited complete SCO, the temperature dependence of $\chi_{\mathrm{M}} T$ data was fitted to the following molecular vibrational partition function (Equation (1)) [27,49,50]:

$$
\chi_{\mathrm{M}} T=\frac{1}{8} \frac{\frac{3}{4} g^{2}+8\left(\frac{\zeta}{k_{\mathrm{B}} T}\right)^{-1}\left[1-\exp \left(-\frac{3}{2} \frac{\zeta}{k_{\mathrm{B}} T}\right)+105 C \exp \left\{-\frac{\zeta}{k_{\mathrm{B}} T}\left(\frac{1+\Delta E}{\zeta}\right)\right\}\right]}{1+2 \exp \left(-\frac{3}{2} \frac{\zeta}{k_{\mathrm{B}} T}\right)+3 C \exp \left\{-\frac{\zeta}{k_{\mathrm{B}} T}\left(\frac{1+\Delta E}{\zeta}\right)\right\}}
$$

where $T$ is the absolute temperature, $g$ is the Lande $g$ factor, $C$ is the molecular partition function ratio in the LS and HS states, and $\zeta$ is the spin-orbit coupling. The adequate parameters determined from fitting the data obtained from 1 are summarized in Table 3 (Figure S6). Compared to values previously reported for related $\mathrm{Fe}^{\mathrm{III}}$ (acen)-type SCO complexes, those of $\mathbf{1}$ are similar in magnitude, whereas those of $\mathbf{2}$ are relatively large in magnitude. These large values of $\mathbf{2}$, in contrast to $\mathbf{1}$, likely result from crystal packing differences brought about by the dense assembly. In fact, the difference in the crystal packing between $\mathbf{1}$ and $\mathbf{2}$ are to be reflected in the thermodynamic parameters (vide infra).

Table 3. Diagnostic spin crossover (SCO) parameters for $\mathbf{1}$ and related complexes.

\begin{tabular}{|c|c|c|c|c|c|}
\hline Complex $^{1}$ & $g^{2}$ & $\zeta\left(\mathrm{cm}^{-1}\right)$ & $\Delta E\left(\mathrm{~cm}^{-1}\right)$ & $C$ & Reference \\
\hline$[\mathrm{Fe}($ acen$)(4-\mathrm{Mepy})]\left[\mathrm{BPh}_{4}\right]$ & 2.14 & 360 & 652 & 76 & {$[50]$} \\
\hline$\left[\mathrm{Fe}(\right.$ acen $\left.)\left(3,4-\mathrm{Me}_{2} \mathrm{py}\right)\right]\left[\mathrm{BPh}_{4}\right]$ & 2.13 & 430 & 528 & 151 & [50] \\
\hline$\left[\mathrm{Fe}(\right.$ acen $)($ bpyp) $]\left[\mathrm{BPh}_{4}\right]$ & 2.14 & 163 & 536 & 76 & {$[49,50]$} \\
\hline 1 & 2.14 & $150(5)$ & $675(7)$ & $125(4)$ & this work \\
\hline 2 & 2.14 & $334(4)$ & 1431(11) & $311(9)$ & this work \\
\hline
\end{tabular}

${ }^{1}$ Ligand abbreviations: 4-Mepy = 4-methylpyridine, 3,4-Me 2 py = 3,4-dimethylpyridine, and bpyp = 1,3-bis(4pyridyl)propane. ${ }^{2}$ Values obtained from EPR spectra, which were fixed in the simulation.

To determine the thermodynamic parameters associated with the thermally induced SCO for $\mathbf{1}$, the enthalpy $(\Delta H)$ and entropy $(\Delta S)$ changes were calculated using the temperature dependence of $\gamma_{\text {HS }}$ (molar fraction of the HS state), which also used the following model proposed by Slichter and Drickamer (Equation (2)) [51]:

$$
T=\frac{\Delta H+\Gamma\left(1-2 \gamma_{\mathrm{HS}}\right)}{R\left(\frac{1-\gamma_{\mathrm{HS}}}{\gamma_{\mathrm{HS}}}\right)+\Delta S}
$$

where $T$ is the absolute temperature, $\Gamma$ is the cooperativity evaluation parameter $\left(C=\Gamma / 2 R T_{1 / 2}\right)$, and $R$ is the gas constant $\left(8.314 \mathrm{~J} \mathrm{~K}^{-1} \mathrm{~mol}^{-1}\right)$. The obtained parameters are listed in Table 4 (Figure S7). The calculated $\Delta S$ values were larger than those expected for SCO between the HS and LS states $\left(R \ln \left(2 S_{\mathrm{HS}}\right.\right.$ $\left.+1) /\left(2 S_{\mathrm{LS}}+1\right)=9.134 \mathrm{~J} \mathrm{~K}^{-1} \mathrm{~mol}^{-1}\right)$, indicating a vibrational contribution to $\Delta S$ associated with bond softening (especially in the ligand-metal bonds) via SCO transition $[52,53]$. The value of $\Gamma$ for 1 and 2 was absent, indicative of a less cooperative SCO. 
Table 4. Thermodynamic parameters and $T_{1 / 2}$ for $\mathbf{1}$ and related complexes.

\begin{tabular}{|c|c|c|c|c|}
\hline Complex ${ }^{1}$ & $\Delta H\left(\mathrm{~kJ} \mathrm{~mol}^{-1}\right)$ & $\Delta S\left(\mathrm{~J} \mathrm{~K}^{-1} \mathrm{~mol}^{-1}\right)$ & $T_{1 / 2}(\mathrm{~K})^{2}$ & Reference \\
\hline$[\mathrm{Fe}($ acen $)(4-\mathrm{Mepy})]\left[\mathrm{BPh}_{4}\right]$ & 12.06 & 50.21 & 240 & [50] \\
\hline$\left[\mathrm{Fe}(\right.$ acen $\left.)\left(3,4-\mathrm{Me}_{2} \mathrm{py}\right)\right]\left[\mathrm{BPh}_{4}\right]$ & 11.25 & 50.21 & 224 & [50] \\
\hline$\left[\mathrm{Fe}(\right.$ acen $)($ bpyp) $]\left[\mathrm{BPh}_{4}\right]$ & 8.88 & 46.02 & 193 & {$[49,50]$} \\
\hline 1 & $8.97(3)$ & $42.25(14)$ & 212 & this work \\
\hline 2 & $19.37(2)$ & $50.42(5)$ & 384 & this work \\
\hline
\end{tabular}

\footnotetext{
${ }^{1}$ Ligand abbreviations: 4-Mepy $=4$-methylpyridine, 3,4-Me 2 py $=3$,4-dimethylpyridine, and bpyp = 1,3-bis $(4-$
} pyridyl)propane. ${ }^{2}$ Values were calculated from $\Delta H / \Delta S$.

While energetic studies of several Fe ${ }^{\mathrm{III}}$ (acen)-type SCO complexes have been previously reported, only one report of $[\mathrm{Fe}($ acen $)(\mathrm{pin})]\left[\mathrm{BPh}_{4}\right] \cdot 3(\mathrm{MeOH})$ showed a relatively abrupt SCO [37]. However, to date, no structurally characterized example of an $\mathrm{Fe}^{\mathrm{III}}$ (acen)-type $\mathrm{SCO}$ complex has been shown to exhibit abrupt and complete SCO, as well as thermal hysteresis. The parameters associated with SCO for the previously reported Fe ${ }^{\mathrm{III}}$ (acen)-type SCO complexes with six-coordinate geometry are summarized in Table 5.

Table 5. Summary of Fe $\mathrm{FII}^{\mathrm{II}}$ (acen)-type SCO complexes.

\begin{tabular}{|c|c|c|c|c|}
\hline Complex ${ }^{1}$ & $\begin{array}{l}\text { Type of } \\
\text { SCO }^{2}\end{array}$ & $\begin{array}{l}T_{1 / 2} \\
(\mathrm{~K})^{3}\end{array}$ & Conformation $^{4}$ & Reference \\
\hline \multicolumn{5}{|c|}{ discrete mononuclear system } \\
\hline$\left[\mathrm{Fe}(\right.$ acen $\left.)(\mathrm{Him})_{2}\right]\left[\mathrm{BPh}_{4}\right]$ & n.a. & n.a. & envelope & {$[30,32,40]$} \\
\hline$\left[\mathrm{Fe}(\right.$ acen $\left.)(\mathrm{py})_{2}\right]\left[\mathrm{BPh}_{4}\right]$ & n.a. & n.a. & n.a. & [30] \\
\hline$\left[\mathrm{Fe}(\right.$ acen $\left.)\left(4-\mathrm{NH}_{2} \mathrm{py}\right)_{2}\right]\left[\mathrm{ClO}_{4}\right]$ & n.a. & n.a. & n.a. & {$[30,40]$} \\
\hline$\left[\mathrm{Fe}(\right.$ acen $\left.)(3-\mathrm{Mepy})_{2}\right]\left[\mathrm{ClO}_{4}\right]$ & n.a. & n.a. & n.a. & [30] \\
\hline$\left[\mathrm{Fe}(\right.$ acen $\left.)(4-\mathrm{Mepy})_{2}\right]\left[\mathrm{BPh}_{4}\right]$ & $\mathrm{g}, \mathrm{c}$ & 240 & n.a. & {$[30,40,50]$} \\
\hline$\left[\mathrm{Fe}(\mathrm{acen})\left(3,4-\mathrm{Me}_{2} \mathrm{py}_{2}\right]\left[\mathrm{BPh}_{4}\right]\right.$ & $\mathrm{g}, \mathrm{c}$ & 224 & meso & {$[34,40,50]$} \\
\hline$\left[\mathrm{Fe}(\right.$ acen $\left.)(1-\mathrm{Buim})_{2}\right]\left[\mathrm{PF}_{6}\right]$ & $\mathrm{g}$, ic & n.a & envelope & [38] \\
\hline$\left[\mathrm{Fe}(\right.$ acen $\left.)(1-\mathrm{Buim})_{2}\right]\left[\mathrm{Tf}_{2} \mathrm{~N}\right]$ & $\mathrm{g}$, ic & n.a & n.a. & [38] \\
\hline \multicolumn{5}{|c|}{ discrete dinuclear system } \\
\hline$(\operatorname{tvpH})\left[\{\mathrm{Fe}(\operatorname{acen})\}_{2}(\mu-\operatorname{tvp})(\operatorname{tvp})(\operatorname{tvpH})\right]\left[\mathrm{BPh}_{4}\right]_{4} \cdot 1.5(\mathrm{MeOH})$ & $\mathrm{g}$, ic & n.a & envelope & [37] \\
\hline \multicolumn{5}{|c|}{ 1D chain system } \\
\hline$\left[\mathrm{Fe}(\right.$ acen)(bpe) $]\left[\mathrm{BPh}_{4}\right]$ & $\mathrm{g}$, ic & n.a & n.a. & [37] \\
\hline$[\mathrm{Fe}($ acen $)(\mathrm{bpdh})]\left[\mathrm{BPh}_{4}\right] \cdot(\mathrm{MeOH})$ & $\mathrm{g}$, ic & n.a & n.a. & [37] \\
\hline$[\mathrm{Fe}($ acen $)($ bix $)]\left[\mathrm{BPh}_{4}\right] \cdot(\mathrm{MeOH})$ & $\mathrm{g}$, ic & n.a & n.a. & [37] \\
\hline$[\mathrm{Fe}($ acen $)(\mathrm{pin})]\left[\mathrm{BPh}_{4}\right] \cdot 3(\mathrm{MeOH})$ & $a, c$ & 135 & n.a. & [37] \\
\hline$\left[\mathrm{Fe}\left(\right.\right.$ acen)(bpyp)][BPh $\left.{ }_{4}\right]$ & $\mathrm{g}, \mathrm{c}$ & 193 & meso & {$[35-37,49,50]$} \\
\hline$[\mathrm{Fe}($ acen $)($ bimb $)]\left[\mathrm{BPh}_{4}\right]$ & $\mathrm{g}$, ic & $\sim 296$ & meso & [36] \\
\hline 1 & $\mathrm{~g}, \mathrm{c}$ & 212 & meso & this work \\
\hline 2 & $\mathrm{~g}$, ic & 384 & envelope & this work \\
\hline
\end{tabular}

1 Abbreviations: Him $=$ imidazole, py $=$ pyridine, $4-\mathrm{NH}_{2}$ py $=4$-aminopyridine, 3-Mepy $=$ 3-methylpyridine, 4-methylpyridine, 3,4-Me 2 py = 3,4-dimethylpyridine, 1-Buim = 1-butylimidazole, $\mathrm{Tf}_{2} \mathrm{~N}=$ bis[(trifluoromethyl)sulfonyl]azanide, tvp = 1,2-bis(4-pyridyl)ethylene, bpe $=1$,2-bis(4-pyridyl)ethane, bpdh $=2,5$-bis(4-pyridyl)-3,4-diaza-2,4-hexadiene, bix = 1,4-bis(1-methylimidazolyl)benzene, pin = N-(4-pyridyl) isonicotinamide, bpyp = 1,3-bis(4-pyridyl)propane, and bimb $=1,4$-bis(imidazolyl)butane. ${ }^{2-4}$ n.a., g, a, c, and ic denote not analyzed, gradual, abrupt, complete, and incomplete, respectively. ${ }^{4}{ }^{4} \mathrm{C}_{2} \mathrm{~N}_{2}$ backbone conformation of the acacen ${ }^{2-}$ ligand.

\section{5. ${ }^{57} \mathrm{Fe}$ Mössßauer Spectroscopy}

For further spectroscopic verification of complete SCO in 1, variable-temperature ${ }^{57} \mathrm{Fe}$ Mössßauer spectra were collected on the polycrystalline solids at select temperatures (Figure 5a) and Table 6). ${ }^{57} \mathrm{Fe}$ Mössßauer spectral data of $\mathbf{2}$ were not collected as the $\mathrm{Fe}^{\mathrm{III}}$ center remained the LS state throughout the measured temperature range. Despite undergoing complete SCO, each ${ }^{57} \mathrm{Fe}$ Mössßauer spectrum of 1 at different temperatures contained only a single symmetric doublet. The observation of the single doublet in the ${ }^{57} \mathrm{Fe}$ Mössßauer spectra of $\mathrm{Fe}^{\mathrm{III}} \mathrm{SCO}$ complexes arises from a rapid electronic relaxation between the LS and HS states. Thus, the electronic relaxation of $\mathbf{1}$ between the two spin states is faster than the time scale of ${ }^{57} \mathrm{Fe}$ Mössßauer spectroscopy $\left(\sim 10^{-7} \mathrm{~s}\right)$, and the ${ }^{57} \mathrm{Fe}$ Mössßauer spectra report the average between the LS and HS states [49,50]. At high temperatures, the respective 
${ }^{57} \mathrm{Fe}$ Mössßauer spectra exhibit an asymmetric quadrupole doublet, due to the spin-lattice relaxation effect [54]. The considerable broadening of the ${ }^{57} \mathrm{Fe}$ Mössßauer spectra with increasing temperature was attributed to the Debye-Waller factor [54]. Indeed, absorption at $300 \mathrm{~K}$ is no more than $\sim 1 \%$ and all spectra could be fitted with a single quadrupole doublet featuring a single line width. The resulting parameters (isomer shifts, $\delta$, quadrupole splittings, $\Delta E_{Q}$, and line widths, $\Gamma$ ) are listed in Table 2 and shown in Figure $5 \mathrm{~b}$. The estimated $\delta, \Delta E_{Q}$, and $\Gamma$ parameters indicated a notable thermal dependence, consistent with the variable-temperature X-band EPR spectra and magnetic susceptibility data (vide supra).

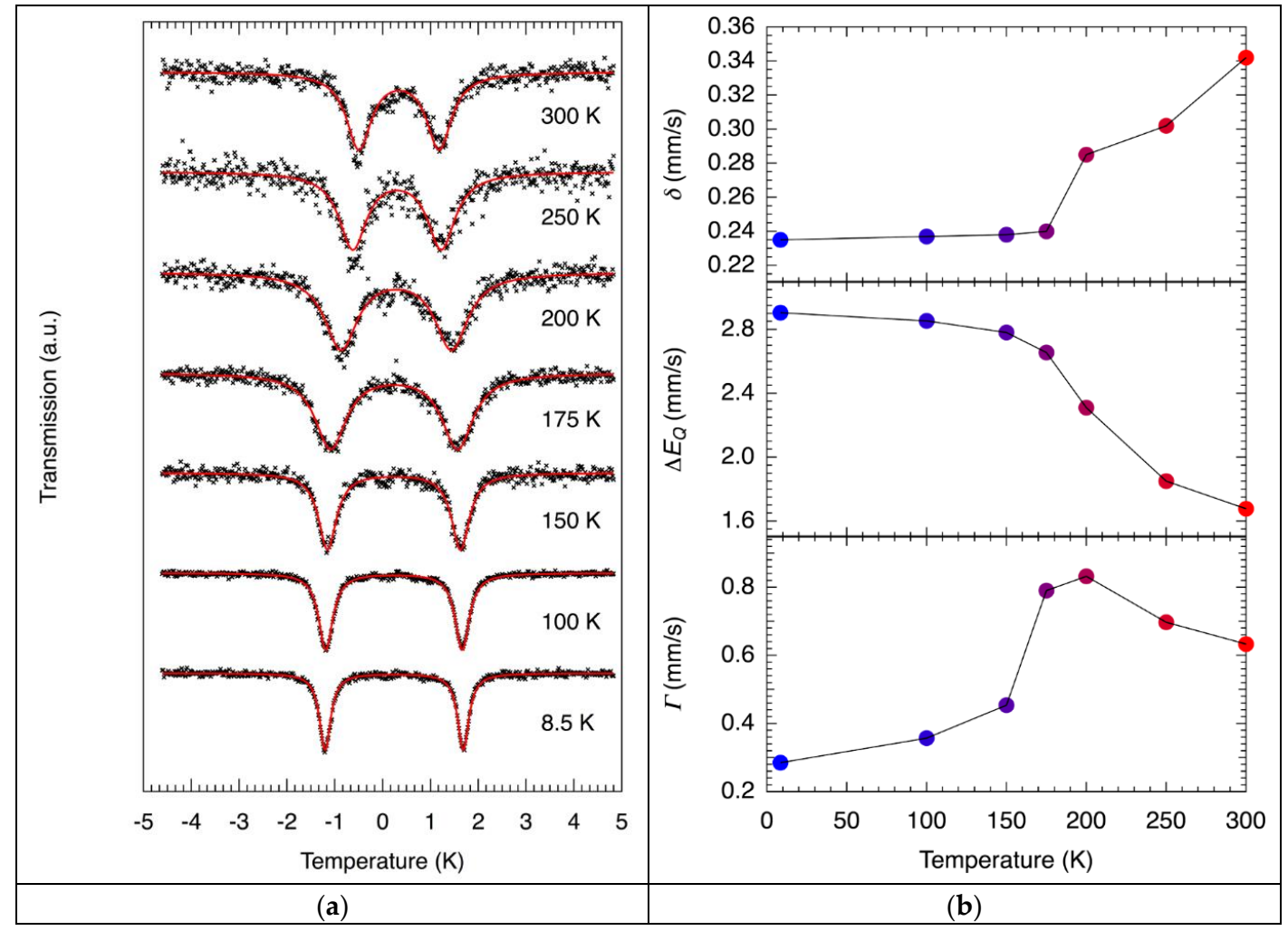

Figure 5. (a) Variable-temperature ${ }^{57} \mathrm{Fe}$ Mössßauer spectra of 1 between 8.5 and $300 \mathrm{~K}$ under zero applied dc magnetic field. Black crosses and solid red lines represent experimental data and fits, respectively. (b) Temperature dependence of $\delta$ (upper plot), $\Delta E_{Q}$ (middle plot), and $\Gamma$ (lower plot) of $\mathbf{1}$. Solid black lines serve as guides.

Table 6. Summary of ${ }^{57} \mathrm{Fe}$ Mössßauer spectral parameters for $\mathbf{1}$.

\begin{tabular}{cccc}
\hline $\boldsymbol{T}(\mathbf{K})$ & $\delta\left(\mathbf{m m ~ s}^{-\mathbf{1}}\right)$ & $\boldsymbol{\Delta} E_{Q}\left(\mathbf{m m ~ s}^{-\mathbf{1}}\right)$ & $\Gamma\left(\mathbf{m m ~ s}^{-\mathbf{1}}\right)$ \\
\hline 300 & $0.342(10)$ & $1.677(20)$ & $0.633(31)$ \\
250 & $0.302(18)$ & $1.850(35)$ & $0.697(50)$ \\
200 & $0.285(12)$ & $2.310(24)$ & $0.832(40)$ \\
175 & $0.240(8)$ & $2.655(16)$ & $0.790(27)$ \\
150 & $0.238(6)$ & $2.781(12)$ & $0.454(19)$ \\
100 & $0.237(7)$ & $2.853(4)$ & $0.357(7)$ \\
8.5 & $0.235(2)$ & $2.905(4)$ & $0.285(6)$ \\
\hline
\end{tabular}

${ }^{1}$ The $\delta$ is referenced to $\alpha$-iron at $300 \mathrm{~K}$. 


\section{Experimental Section}

\subsection{Material and Methods}

Anhydrous $\mathrm{FeCl}_{3}, \mathrm{MeOH}$, and $\mathrm{EtOH}$ were purchased from Wako Pure Chemical Industries, Ltd. (Osaka, Japan). 3,3'-bpy, 4,4'-bpy, and $\mathrm{NaBPh}_{4}$ were purchased from Tokyo Chemical Industry (TCI) Co., Ltd. (Tokyo, Japan). All chemicals were of reagent grade and were used as received. All reactions and manipulations were performed under aerobic conditions at $20^{\circ} \mathrm{C}$. [ Fe(acen) $\mathrm{Cl}$ ] was prepared using the published procedure $[29,30]$.

\subsection{Synthesis of $\left[\mathrm{Fe}(\right.$ acen $\left.)\left(3,3^{\prime}-b p y\right)\right]\left[B P h_{4}\right](\mathbf{1})$}

A colorless solution of 3,3'-bpy (78 $\mathrm{mg}, 0.5 \mathrm{mmol})$ in $10 \mathrm{~mL} \mathrm{MeOH}$ was added dropwise to a stirred purple solution of [Fe(acen)Cl] $(157 \mathrm{~g}, 0.5 \mathrm{mmol})$ in $30 \mathrm{~mL}$ of MeOH, affording a green mixture. The mixture was stirred and heated at $50{ }^{\circ} \mathrm{C}$ for $15 \mathrm{~min}$ and then hot filtered. A colorless solution of $\mathrm{NaBPh}_{4}(171 \mathrm{mg}, 0.5 \mathrm{mmol})$ in $30 \mathrm{~mL} \mathrm{MeOH}$ was added to the hot filtrate. The resulting dark green solution was allowed to stand for several days at $20{ }^{\circ} \mathrm{C}$, to afford dark green block-shaped crystals. The crystals were collected via filtration, washed with a small amount of ice-cold $\mathrm{MeOH}$, and subsequently air-dried. Yield: $196 \mathrm{mg}$ (52\%). IR (ATR): $v_{\mathrm{B}-\mathrm{C}}=701$ and $733 \mathrm{~cm}^{-1}$, and $v_{\mathrm{C}=\mathrm{N}}=1580$ $\mathrm{cm}^{-1}$. Anal. Calcd. For $\mathrm{C}_{46} \mathrm{H}_{46} \mathrm{BFeN}_{4} \mathrm{O}_{2}$ : C, 73.32\%; H, 6.15\%, N, 7.44\%. Found: C, 73.28\%; H, 6.21\%, N, 7.37\%. Phase purity was confirmed by PXRD measurements.

\subsection{Synthesis of $\left[N E t_{3} H\right]\left[F e(a c e n)\left(4,4^{\prime}-b p y\right)\right]\left[B P h_{4}\right]_{2} \cdot 0.5\left(4,4^{\prime}-b p y\right)(2)$}

A colorless solution of $\mathrm{H}_{2}$ acen $(112 \mathrm{mg}, 0.5 \mathrm{mmol})$ in $40 \mathrm{~mL} \mathrm{MeOH}$ was added to solid anhydrous $\mathrm{FeCl}_{3}(81 \mathrm{mg}, 0.5 \mathrm{mmol})$. To the resulting mixture, $\mathrm{NEt}_{3}(101 \mathrm{mg}, 1 \mathrm{mmol})$ was added dropwise, and stirred and heated at $50{ }^{\circ} \mathrm{C}$ for $15 \mathrm{~min}$, during which time the color of the reaction mixture changed from red to purple. Solid 4,4'-bpy (78 $\mathrm{mg}, 0.5 \mathrm{mmol}$ ) was then added, and the reaction mixture was stirred for another $15 \mathrm{~min}$ and subsequently hot filtered. A colorless solution of $\mathrm{NaBPh}_{4}(171 \mathrm{mg}, 0.5 \mathrm{mmol})$ in $30 \mathrm{~mL} \mathrm{MeOH}$ was added to the hot filtrate. The resulting dark green solution was allowed to stand for several days at $20^{\circ} \mathrm{C}$, affording dark green plate-shaped crystals. The crystals were collected via filtration, washed with a small amount of ice-cold $\mathrm{MeOH}$, and subsequently air-dried. Yield: $232 \mathrm{mg}$ (37\%). IR (ATR): $v_{\mathrm{B}-\mathrm{C}}=704$ and $733 \mathrm{~cm}^{-1}$, and $v_{\mathrm{C}=\mathrm{N}}=1580 \mathrm{~cm}^{-1}$. Anal. Calcd. For $\mathrm{C}_{81} \mathrm{H}_{86} \mathrm{~B}_{2} \mathrm{FeN}_{6} \mathrm{O}_{2}$ : C, 77.64\%; H, 6.92\%, N, 6.71\%. Found: C, 77.29\%; H, 6.88\%, N, 6.56\%. Phase purity was confirmed by PXRD measurements.

\subsection{Single Crystal X-ray Crystallography}

Single crystals of $\mathbf{1}$ and $\mathbf{2}$ were coated with Nujol, quickly mounted on MicroLoops (MiTeGen LLC., Ithaca, NY, USA), and immediately cooled in a cold dinitrogen stream. The data collections were performed on a R-AXIS RAPID II IP diffractometer (Rigaku Corporation, Tokyo, Japan) with graphite-monochromated Mo-K $\alpha$ radiation $(\lambda=0.71075 \AA)$ and a low-temperature device. The data integration, preliminary data analysis, and absorption collections were performed on a Rigaku CrystalClear-SM 1.4.0 SP1 [55], using the CrystalStructure 4.2.2 [56] crystallographic software packages. The molecular structures were solved by the direct methods included in SIR2011 [57] and refined with the SHELXL [58] program. All non-hydrogen atoms were refined anisotropically. CCDC 2007100-2007103 for 1 and $\mathbf{2}$ contain the supplementary crystallographic data for this paper and can be obtained free of charge via www.ccdc.cam.ac.uk/data_request/cif, or by emailing data_request@ccdc.cam.ac.uk, or by contacting The Cambridge Crystallographic Data Centre, 12 Union Road, Cambridge CB2 1EZ, UK; fax: +441223 336033. All the hydrogen atoms were included in the calculated positions. Table S1 summarizes the lattice constants and structure refinement parameters for complexes $\mathbf{1}$ and 2. 


\subsection{Physical Measurements}

The elemental analyses were performed on a J-Science Lab Micro Corder JM10 (J-Science Lab Co., Ltd., Kyoto, Japan). IR spectra were recorded on a JASCO FT/IR-6200 spectrometer equipped with an attenuated total reflectance accessory (ATR) (JASCO Corporation, Tokyo, Japan) in the range of $650-4000 \mathrm{~cm}^{-1}$ at $293 \mathrm{~K}$. PXRD data were collected at $293 \mathrm{~K}$ with a RIGAKU MultiFlex diffractometer (Rigaku Corporation, Tokyo, Japan) $(50 \mathrm{kV} / 32 \mathrm{~mA}, 1.6 \mathrm{~kW})$ with $\mathrm{Cu} \mathrm{K} \alpha$ radiation $(\lambda=1.5406 \AA)$ in the $2 \theta$ range of $5-50^{\circ}$ and a step width of $0.02^{\circ}$. TGA were carried out on a Seiko Instruments SSC5200 Thermo Analyzer (Seiko Instruments Inc., Tokyo, Japan), with a heating rate of $10 \mathrm{~K} \mathrm{~min}^{-1}$ in the temperature range of 293-550 K, under a $\mathrm{N}_{2}$ atmosphere. For CW X-band EPR measurements, finely ground microcrystalline powders were sealed in quartz tubes of $4 \mathrm{~mm}$ diameter under a $\mathrm{N}_{2}$ atmosphere. EPR spectra were recorded on a Bruker EMXmicro spectrometer equipped with a continuous flow liquid $\mathrm{N}_{2}$ cryostat and a temperature controller (Bruker BioSpin Ltd., Yokohama, Japan). All EPR spectra were analyzed with the Bruker Xenon software package (Bruker BioSpin Ltd., Yokohama, Japan). All the EPR data were collected under the following experimental conditions: microwave frequency, $9.44 \mathrm{GHz}$; microwave power, $0.11 \mathrm{~mW}$; modulation amplitude, $4 \mathrm{G}$; modulation frequency, $100 \mathrm{kHz}$. The magnetic data were collected using a Quantum Design MPMSXL7 SQUID magnetometer (Quantum Design Japan, Inc., Tokyo Japan). The measurements were performed with polycrystalline samples in a calibrated gelatin capsule. The dc magnetic susceptibility measurements were performed in the temperature range of $2-400 \mathrm{~K}$ in a dc field of $0.5 \mathrm{~T}$. The obtained dc magnetic susceptibility data were corrected for diamagnetic contributions from the sample holder, as well as for the core diamagnetism of each sample, estimated from Pascal's constants [59]. DSC measurements were carried out on a Seiko Instruments EXSTAR DSC 6200 Differential Scanning Calorimeter (Seiko Instruments Inc., Tokyo, Japan) with a heating rate of $10 \mathrm{~K} \mathrm{~min}^{-1}$ in the temperature range of $150-350 \mathrm{~K}$ under a $\mathrm{N}_{2}$ atmosphere. The Mössbauer spectra were measured between 8.5, 100, 150, 175, 200, 250, and $300 \mathrm{~K}$, respectively, and performed with a Wissel MVT-1000 Mössßauer spectrometer (Wissenschaftliche Elektronik GmbH, Starnberg, Germany), with a ${ }^{57} \mathrm{Co} / \mathrm{Ph}$ source equipped with a closed-cycle He refrigerator cryostat in transmission mode. All spectra were calibrated at $300 \mathrm{~K}$ with $\alpha$-Fe and were fitted using the MossA software package [60].

\section{Conclusions}

Two novel 3,3'- and 4,4'-bipyridine-bridged Fe ${ }^{\mathrm{III}} 1 \mathrm{D}$ chain complexes (1 and $\left.\mathbf{2}\right)$ were synthesized herein using a cationic mononuclear precursor, $\left[\mathrm{Fe}^{\mathrm{III}} \text { (acen) }\right]^{+}$, as a building unit for constructing $1 \mathrm{D}$ $\mathrm{Fe}^{\mathrm{III}}$ spin crossover coordination polymers. The SCXRD structures of $\mathbf{1}$ and $\mathbf{2}$ featured 1D chains, which can be considered as extended 1D zigzag and linear coordination polymer arrangements, respectively. Notably, 1 underwent thermally induced gradual and complete SCO with a transition temperature of $212 \mathrm{~K}$, whereas 2 also showed thermally induced incomplete SCO even at $400 \mathrm{~K}$. Current efforts are focusing on preparing coordination architectures with higher dimensionality, such as two-dimensional layers and three-dimensional MOF-like structures, which may induce cooperative SCO behavior, accompanied by abrupt and wide thermal hysteresis.

Supplementary Materials: The following are available online at http://www.mdpi.com/2312-7481/6/3/29/s1, Table S1: Single crystal X-ray crystallographic data for 1 and 2.; Table S2: Comparison of coordination bond distances for 1, 2, and related complexes.; Figure S1: FTIR spectra for $\mathbf{1}$ and 2.; Figure S2: PXRD data for $\mathbf{1}$ and 2.; Figure S3: TG profiles for 1 and 2.; Figure S4: View of $\mathrm{N}-\mathrm{H} \cdots \mathrm{N}$ hydrogen bonding interactions between $\mathrm{NEt}_{3} \mathrm{H}$ and 4,4'-bpy for 2.; and Figure S5: DSC curves for 1.; Figure S6: Temperature dependence of $\chi_{\mathrm{M}} T$ data with best fits for $\mathbf{1}$ and 2.; Figure S7: Temperature dependence of $\gamma_{\mathrm{HS}}$ data with best fits for $\mathbf{1}$ and $\mathbf{2}$.

Author Contributions: Conceptualization, R.I.; Data Curation, R.I.; Formal Analysis, R.I. and S.K.; Funding acquisition, R.I., T.O. and S.K.; Investigation, R.I., T.N., S.U., T.O., H.Y. and K.-i.S.; Methodology, R.I.; Software, R.I. and S.K.; Project Administration, R.I.; Resources, R.I.; Supervision, S.K.; Validation, R.I., T.O. and S.K.; Visualization, R.I.; Writing-Original Draft Preparation, R.I.; Writing-Review and Editing, R.I., T.O. and S.K. All authors have read and agreed to the published version of the manuscript. 
Funding: This work was supported financially by the Ministry of Education, Culture, Sports, Science and Technology (MEXT) KAKENHI (Grant-in-Aid for Scientific Research on Innovative Areas), Grant Number $18 \mathrm{H} 04529$ and $18 \mathrm{H} 04527$ "Soft Crystals" to R.I. and T.O. This work was also supported financially by the Central Research Institute of Fukuoka University, Grant Number 171041 and 171011 to R.I. and S.K.

Conflicts of Interest: The authors declare no conflict of interest.

\section{References}

1. Sato, O. Optically Switchable Molecular Solids: Photoinduced Spin-Crossover, Photochromism, and Photoinduced Magnetization. Acc. Chem. Res. 2003, 36, 692-700. [CrossRef] [PubMed]

2. Gütlich, P.; Goodwin, H.A. Spin Crossover in Transition Metal Compounds I-III, Topics in Current Chemistry; Springer: Berlin, Germany, 2004.

3. Murray, K.S. Advances in polynuclear iron(II), iron(III) and cobalt(II) spin-crossover compounds. Eur. J. Inorg. Chem. 2008, 2008, 3101-3121. [CrossRef]

4. Gamez, P.; Costa, J.S.; Quesada, M.; Aromí, G. Iron Spin-Crossover compounds: From fundamental studies to practical applications. Dalton Trans. 2009, 38, 7845-7853. [CrossRef] [PubMed]

5. Halcrow, M.A. Structure:function relationships in molecular spin-crossover complexes. Chem. Soc. Rev. 2011, 40, 4119-4142. [CrossRef]

6. Gütlich, P.; Gaspar, A.B.; Garcia, Y. Spin state switching in iron coordination compounds. Beilstein J. Org. Chem. 2013, 9, 342-391. [CrossRef]

7. Halcrow, M.A. Spin-Crossover Materials: Properties and Applications, 1st ed.; John Wiley \& Sons, Ltd.: Chichester, UK, 2013.

8. Halcrow, M.A. Spin-crossover Compounds with Wide Thermal Hysteresis. Chem. Lett. 2014, 43, 1178-1188. [CrossRef]

9. Brooker, S. Spin crossover with thermal hysteresis: Practicalities and lessons learnt. Chem. Soc. Rev. 2015, 44, 2880-2892. [CrossRef]

10. Sato, O. Dynamic molecular crystals with switchable physical properties. Nat. Chem. 2016, 8, $644-656$. [CrossRef] [PubMed]

11. Meng, Y.-S.; Liu, T. Manipulating Spin Transition to Achieve Switchable Multifunctions. Acc. Chem. Res. 2019, 52, 1369-1379. [CrossRef]

12. Kahn, O.; Martinez, C.J. Spin-Transition Polymers: From Molecular Materials toward Memory Devices. Science 1998, 279, 44-48. [CrossRef]

13. Gaspar, A.B.; Ksenofontov, V.; Seredyuk, M.; Gütlich, P. Multifunctionality in spin crossover materials. Coord. Chem. Rev. 2005, 249, 2661-2676. [CrossRef]

14. Bousseksou, A.; Molnár, G.; Salmon, L.; Nicolazzi, W. Molecular spin crossover phenomenon: Recent achievements and prospects. Chem. Soc. Rev. 2011, 40, 3313-3335. [CrossRef] [PubMed]

15. Shepherd, H.J.; Gural'skiy, I.A.; Quintero, C.M.; Tricard, S.; Salmon, L.; Molnár, G.; Bousseksou, A. Molecular actuators driven by cooperative spin-state switching. Nat. Commun. 2013, 4, 2607. [CrossRef]

16. Gaspar, A.B.; Seredyuk, M. Spin crossover in soft matter. Coord. Chem. Rev. 2014, 268, 41-58. [CrossRef]

17. Gentili, D.; Demitri, N.; Schäfer, B.; Liscio, F.; Bergenti, I.; Ruani, G.; Ruben, M.; Cavallini, M. Multi-modal sensing in spin crossover compounds. J. Mater. Chem. C 2015, 3, 7836-7844. [CrossRef]

18. Lefter, C.; Davesne, V.; Salmon, L.; Molnár, G.; Demont, P.; Rotaru, A.; Bousseksou, A. Charge Transport and Electrical Properties of Spin Crossover Materials: Towards Nanoelectronic and Spintronic Devices. Magnetochemistry 2016, 2, 18. [CrossRef]

19. Kumar, K.S.; Ruben, M. Emerging trends in spin crossover (SCO) based functional materials and devices. Coord. Chem. Rev. 2017, 346, 176-205. [CrossRef]

20. Armand, F.; Badoux, C.; Bonville, P.; Ruaudel-Teixier, A.; Kahn, O. Langmuir-Blodgett Films of Spin Transition Iron(II) Metalloorganic Polymers. 1. Iron(II) Complexes of Octadecyl-1,2,4-triazole. Langmuir 1995, 11, 3467-3472. [CrossRef]

21. Cobo, S.; Molnár, G.; Real, J.A.; Bousseksou, A. Multilayer Sequential Assembly of Thin Films That Display Room-Temperature Spin Crossover with Hysteresis. Angew. Chem. Int. Ed. 2006, 45, 5786-5789. [CrossRef] 
22. Molnár, G.; Cobo, S.; Real, J.A.; Carcenac, F.; Daran, E.; Vieu, C.; Bousseksou, A. A Combined Top-Down/Bottom-Up Approach for the Nanoscale Patterning of Spin-Crossover Coordination Polymers. Adv. Mater. 2007, 19, 2163-2167. [CrossRef]

23. Agustí, G.; Cobo, S.; Gaspar, A.B.; Molnár, G.; Moussa, N.O.; Szilágyi, P.Á.; Pálfi, V.; Vieu, C.; Carmen Muñoz, M.; Real, J.A.; et al. Thermal and Light-Induced Spin Crossover Phenomena in New 3D Hofmann-Like Microporous Metalorganic Frameworks Produced as Bulk Materials and Nanopatterned Thin Films. Chem. Mater. 2008, 20, 6721-6732. [CrossRef]

24. Cavallini, M.; Bergenti, I.; Milita, S.; Ruani, G.; Salitros, I.; Qu, Z.-R.; Chandrasekar, R.; Ruben, M. Microand Nanopatterning of Spin-Transition Compounds into Logical Structures. Angew. Chem. Int. Ed. 2008, 47, 8596-8600. [CrossRef]

25. Cavallini, M. Inhomogeneous thin deposits: A strategy to exploit their functionality. J. Mater. Chem. 2009, 19, 6085-6092. [CrossRef]

26. Cavallini, M.; Bergenti, I.; Milita, S.; Kengne, J.C.; Gentili, D.; Ruani, G.; Salitros, I.; Meded, V.; Ruben, M. Thin Deposits and Patterning of Room-Temperature-Switchable One-Dimensional Spin-Crossover Compounds. Langmuir 2011, 27, 4076-4081. [CrossRef] [PubMed]

27. Nihei, M.; Shiga, T.; Maeda, Y.; Oshio, H. Spin crossover iron(III) complexes. Coord. Chem. Rev. 2007, 251, 2606-2621. [CrossRef]

28. Harding, D.J.; Harding, P.; Phonsri, W. Spin crossover in iron(III) complexes. Coord. Chem. Rev. 2016, 313, 38-61. [CrossRef]

29. Gerloch, M.; Lewis, J.; Mabbs, F.E.; Richards, A. The preparation and magnetic properties of some Schiff base-iron(III) halide complexes. J. Chem. Soc. A. 1968, 112-116. [CrossRef]

30. Nishida, U.; Oshio, S.; Kida, S. Synthesis and Magnetic Properties of Iron(III) Complexes with Several Quadridentate Schiff Bases. Bull. Chem. Soc. Jpn. 1977, 50, 119-122. [CrossRef]

31. McCusker, J.K.; Rheingold, A.L.; Hendrickson, D.N. Studies of Laser-Initiated ${ }^{5} \mathrm{~T}_{2} \rightarrow{ }^{1} \mathrm{~A}_{1}$ Intersystem Crossing in Spin-Crossover Complexes: Empirical Correlations between Activation Parameters and Ligand Structure. Inorg. Chem. 1996, 35, 2100-2112. [CrossRef]

32. Nishida, Y.; Kino, K.; Kida, S. Crystal structures of low- and high-spin iron(III) complexes with quadridentate Schiff bases. J. Chem. Soc. Dalton Trans. 1987, 1157-1161. [CrossRef]

33. Wang, X.; Pennington, W.T.; Ankers, D.L.; Fanning, J.C. Comparative crystal structure examination of some iron(III) quadridentate schiff base complexes. Polyhedron 1992, 11, 2253-2264. [CrossRef]

34. Maeda, Y.; Oshio, H.; Toriumi, K.; Takashima, Y. Crystal structures, mössbauer spectra and magnetic properties of two iron(III) spin-crossover complexes. J. Chem. Soc. Dalton Trans. 1991, 1227-1235. [CrossRef]

35. Imatomi, S.; Kitashima, R.; Hamamastu, T.; Okeda, M.; Ogawa, Y.; Matsumoto, N. One-dimensional Polynuclear Spin-crossover Iron(III) Complex Axially Bridged by 1,3-Bis(4-pyridyl)propane. Chem. Lett. 2006, 35, 502-503. [CrossRef]

36. Imatomi, S.; Hashimoto, S.; Matsumoto, N. Inter- and intrachain spin-transition processes in one-dimensional polynuclear iron(III) complexes of $N, N^{\prime}$-ethylenebis(acetylacetonylideneimine) bridged by 1,3-bis(4-pyridyl)propane and 1,4-bis(imidazolyl)butane. Eur. J. Inorg. Chem. 2009, 721-726. [CrossRef]

37. Ross, T.M.; Neville, S.M.; Innes, D.S.; Turner, D.R.; Moubaraki, B.; Murray, K.S. Spin crossover in iron(III) Schiff-base 1-D chain complexes. Dalton Trans. 2010, 39, 149-159. [CrossRef]

38. Okuhata, M.; Funasako, Y.; Takahashi, K.; Mochida, T. A spin-crossover ionic liquid from the cationic iron(iii) Schiff base complex. Chem. Commun. 2013, 49, 7662-7664. [CrossRef] [PubMed]

39. Krzystek, J.; Ozarowski, A.; Telser, J. Multi-frequency, high-field EPR as a powerful tool to accurately determine zero-field splitting in high-spin transition metal coordination complexes. Coord. Chem. Rev. 2006, 250, 2308-2324. [CrossRef]

40. Nishida, Y.; Oshio, S.; Kida, S. ESR spectra of low-spin iron(III) complexes with several quadridentate schiff bases. Inorganica Chim. Acta 1977, 23, 59-61. [CrossRef]

41. Shongwe, M.S.; Al-Rashdi, B.A.; Adams, H.; Morris, M.J.; Mikuriya, M.; Hearne, G.R. Thermally Induced Two-Step, Two-Site Incomplete ${ }^{6} \mathrm{~A}_{1} \leftrightarrow{ }^{2} \mathrm{~T}_{2}$ Crossover in a Mononuclear Iron(III) Phenolate-Pyridyl Schiff-Base Complex: A Rare Crystallographic Observation of the Coexistence of Pure $S=5 / 2$ and 1/2 Metal Centers in the Asymmetric Unit. Inorg. Chem. 2007, 46, 9558-9568. [CrossRef] 
42. Tang, J.; Sánchez Costa, J.; Smulders, S.; Molnár, G.; Bousseksou, A.; Teat, S.J.; Li, Y.; van Albada, G.A.; Gamez, P.; Reedijk, J. Two-Step Spin-Transition Iron(III) Compound with a Wide [High Spin-Low Spin] Plateau. Inorg. Chem. 2009, 48, 2128-2135. [CrossRef] [PubMed]

43. Shongwe, M.S.; Al-Rahbi, S.H.; Al-Azani, M.A.; Al-Muharbi, A.A.; Al-Mjeni, F.; Matoga, D.; Gismelseed, A.; Al-Omari, I.A.; Yousif, A.; Adams, H.; et al. Coordination versatility of tridentate pyridyl aroylhydrazones towards iron: Tracking down the elusive aroylhydrazono-based ferric spin-crossover molecular materials. Dalton Trans. 2012, 41, 2500-2514. [CrossRef] [PubMed]

44. Domracheva, N.E.; Pyataev, A.V.; Vorobeva, V.E.; Zueva, E.M. Detailed EPR Study of Spin Crossover Dendrimeric Iron(III) Complex. J. Phys. Chem. B 2013, 117, 7833-7842. [CrossRef] [PubMed]

45. Pogány, L.; Brachňaková, B.; Moncol, J.; Pavlik, J.; Nemec, I.; Trávníček, Z.; Mazúr, M.; Bučinský, L.; Suchánek, L.; Šalitroš, I. Impact of Substituent Variation on the Presence of Thermal Spin Crossover in a Series of Mononuclear Iron(III) Schiff Base Complexes with Terminal Pseudohalido Co-ligands. Chem. Eur. J. 2018, 24, 5191-5203. [CrossRef] [PubMed]

46. Dey, B.; Roy, S.; Titiš, J.; Boča, R.; Bera, S.P.; Mondal, A.; Konar, S. Above Room Temperature Spin Transition in Thermally Stable Mononuclear Fe(III) Complexes. Inorg. Chem. 2019, 58, 1134-1146. [CrossRef] [PubMed]

47. Sundaresan, S.; Kühne, I.A.; Kelly, C.T.; Barker, A.; Salley, D.; Müller-Bunz, H.; Powell, A.K.; Morgan, G.G. Anion Influence on Spin State in Two Novel Fe(III) Compounds: [Fe(5F-sal2333)]X. Crystals 2019, 9, 19. [CrossRef]

48. Aasa, R. Powder Line Shapes in the Electron Paramagnetic Resonance Spectra of High-Spin Ferric Complexes. J. Chem. Phys. 1970, 52, 3919-3930. [CrossRef]

49. Maeda, Y.; Ohshio, H.; Takashima, Y. Rapid Electronic Relaxation Phenomenon in the Transition between ${ }^{6} \mathrm{~A}_{1}$ and ${ }^{2} \mathrm{~T}_{2}$ states. Chem. Lett. 1982, 11, 943-946. [CrossRef]

50. Ohshio, H.; Maeda, Y.; Takashima, Y. Rapid Electronic Relaxation Phenomenon in a ${ }^{2} \mathrm{~T}{ }^{6} \mathrm{~A}$ Spin-Equilibrium System. Inorg. Chem. 1983, 22, 2684-2689. [CrossRef]

51. Slichter, C.P.; Drickamer, H.G. Pressure-Induced Electronic Changes in Compounds of Iron. J. Chem. Phys. 1972, 56, 2142-2160. [CrossRef]

52. Sorai, M.; Seki, S. Phonon coupled cooperative low-spin 1A1high-spin $5 \mathrm{~T} 2$ transition in $\left[\mathrm{Fe}(\mathrm{phen})_{2}(\mathrm{NCS})_{2}\right]$ and [Fe(phen $)_{2}(\mathrm{NCSe})_{2}$ ] crystals. J. Phys. Chem. Solids 1974, 35, 555-570. [CrossRef]

53. Nakamoto, T.; Tan, Z.-C.; Sorai, M. Heat Capacity of the Spin Crossover Complex $\left[\mathrm{Fe}(2-\mathrm{pic})_{3}\right] \mathrm{Cl}_{2} \cdot \mathrm{MeOH}$ A Spin Crossover Phenomenon with Weak Cooperativity in the Solid State. Inorg. Chem. 2001, 40, 3805-3809. [CrossRef] [PubMed]

54. Gütlich, P.; Bill, E.; Trautwein, A.X. Mössbauer Spectroscopy and Transition Metal Chemistry, Fundamentals and Applications; Springer: Berlin, Germany, 2011.

55. CrystalClear-SM; Version 1.4.0 SP1; Rigaku and Rigaku/MSC: The Woodlands, TX, USA, 2008.

56. CrystalStructure; Version 4.2.2; Rigaku and Rigaku/MSC: The Woodlands, TX, USA, 2017.

57. Burla, M.C.; Caliandro, R.; Camalli, M.; Carrozzini, B.; Cascarano, G.L.; Giacovazzo, C.; Mallamo, M.; Mazzone, A.; Polidori, G.; Spagna, R. SIR2011: A new package for crystal structure determination and refinement. J. Appl. Crystallogr. 2012, 45, 357-361. [CrossRef]

58. Sheldrick, G.M. Crystal structure refinement with SHELXL. Acta Crystallogr. Sect. C 2015, 71, 3-8. [CrossRef]

59. Bain, G.A.; Berry, J.F. Diamagnetic Corrections and Pascal's Constants. J. Chem. Educ. 2008, 85, 532. [CrossRef]

60. Prescher, C.; McCammon, C.; Dubrovinsky, L. MossA: A program for analyzing energy-domain Mössbauer spectra from conventional and synchrotron sources. J. Appl. Crystallogr. 2012, 45, 329-331. [CrossRef]

(C) 2020 by the authors. Licensee MDPI, Basel, Switzerland. This article is an open access article distributed under the terms and conditions of the Creative Commons Attribution (CC BY) license (http://creativecommons.org/licenses/by/4.0/). 